\title{
Fuzzy Control of Active Suspension System using Full Car Model
}

\author{
P. SENTHILKUMAR*, K. SIVAKUMAR**, R. KANAGARAJAN***, S. KUBERAN**** \\ *Department of Mechanical Engineering, Bannari Amman Institute of Technology, India-638401, \\ E-mail: bitsenthil@gmail.com \\ **Department of Mechanical Engineering, Bannari Amman Institute of Technology, India-638401, \\ E-mail: ksksiddarth@gmail.com \\ ***Department of Mechanical Engineering, Bannari Amman Institute of Technology, India-638401, \\ E-mail: kanagarajan.me14@bitsathy.ac.in \\ ****Department of Mechanical Engineering, Bannari Amman Institute of Technology, India-638401, \\ E-mail: kuberan.me14@bitsathy.ac.in \\ cross $^{\text {ref }}$ http://dx.doi.org/10.5755/j01.mech.24.2.17457
}

\section{Introduction}

A suspension system consists of spring and oil damper connected between vehicle body and tire to control the vertical moment of car body. The main purpose of suspension system is to reduce the effect of road disturbance on vehicle body by minimizing the displacement and acceleration of vehicle body. The main objective of suspension system is to provide ride comfort for passenger which depends on soft suspension system and better road handling capacity which depends on hard suspension. Design of suspension involves an optimization process where the design elements are selected by compromising on soft and hard suspension. A suspension system classified into passive suspension, semi active suspension and active suspension. A passive suspension system does not require any external energy source and its damping coefficient values are almost constant. In active suspension, force actuator placed in between wheel and vehicle body along with suspension system. The active suspension systems are closed loop systems where the suspension travel of suspension system measured to predict the actuator force needed for active suspension system. Nowadays, many researcher focusing research on active suspension systems [1] due to its ability to operate wide range frequency. The development of computer and microprocessor improved practical implementation of active suspension [2-3] in automotive industries.

A quarter car model consists of one fourth of vehicle mass, spring and damper connected between wheels' mass has been used to design a controller for active suspension system. The quarter car model is a simplified model of car with two degree of freedom by using that the vertical motion of car body and wheel has been measured for active suspension. The quarter car model will be used to represent heave motion of one fourth of vehicle mass. Initially, the controller for quarter car active suspension system designed without considering the dynamics of actuator. But it cannot be used to measure the pitch motion of front wheel and rear wheel. Alleyne et al [4] proposed a nonlinear control technique for hydraulic operated quarter car active suspension. A nonlinear control law formulated to control dynamic nature of hydraulic actuator.

Half car model with four degree of freedom will be used to represent pitch and heave motion of vehicle body. Vehicle body coupled between front and rear wheel by cen- tre of gravity. Nurkan Yagiz [5] proposed sliding mode control combined with Fuzzy logic for nonlinear half car model. The effect of chattering in sliding mode control can be eliminated completely by adding fuzzy controller for half car model. Both quarter car and half car model does not model the actual system for practical application. Accurate model of the actual system need full car model with seven degree of freedom. A full car model of active suspension system is developed by considering seven degrees of freedom namely four vertical motion of wheel, pitch, roll and heave motion of vehicle body. H infinity controller [6] introduced for full car model to suppress the effect of road disturbances and parameter uncertainty in actuator dynamics. A preview controller for full car model [7] based active suspension introduced with two control approach. The first controller optimizes the displacement of actuator whereas the second controller control the pitch, heave and roll motion of vehicle body. The complexity of mathematical model of full car and nonlinear behaviour of actuator has increased the difficulties of applying conventional control schemes to active suspension system. Hence a model free controller based on intelligent control schemes like fuzzy logic, neural network is gaining more importance in recent times and they are applied success fully to control suspension system in real time.

The Fuzzy logic introduced by Lotfi Zadeh in his seminar paper fuzzy set theory [8] in 1965.Fuzzy logic is based on multi value logic where the true values lies in between 1 and 0 . The performance of fuzzy depends on type and nature of linguistic variable whereas the values of variable graded using membership function. Fuzzy rules are written based on knowledge of system and then it will be converted in to equivalent mathematical model of a system. Fuzzy controller is simple and flexible hence it can handle imprecise data very well. Fuzzy logic can easily model the nonlinear function of any system.

Mamdani [9-10] introduced fuzzy logic in control system for practical application. The control rules in fuzzy logic is written based on the knowledge of expert. Fuzzy logic has ability to develop controller without any mathematical model of a system. The complex nonlinear behaviour of actuator and its dynamics has been controlled effectively using fuzzy logic controller. Fuzzy logic controller for quarter car active suspension [11] proposed with inputs as suspension deflection and its change and the output as the change of the control signal. An active suspension system proposed for a half-car model where the active control is the 
sum of two kinds of control. Fuzzy logic algorithm [12-14] for quarter car model was developed for better ride comfort using hybrid intelligent algorithm.

Expert's knowledge and experience plays an important role in creating fuzzy rules for conventional fuzzy logic controller. So, there is no proper guideline for selecting rules and parameter for fuzzy controller. Quarter car model based active suspension with Self-organizing fuzzy sliding mode controller (SFSC) created using sliding surface [15] and its change as input to fuzzy controller. The stability of system improved by adaptive law of SFSC. Type-2 fuzzy controller is proposed to resolve nonlinear control problems of active suspension systems [16-21] which integrates the Takagi-Sugeno (T-S) fuzzy model, interval type-2 fuzzy reasoning method. A fuzzy sliding-mode controller for active suspensions [22] of a nonlinear half-car model is introduced to remove non chattering effect in sliding-mode control. In this method, sliding mode controller combined with a single-input-single-output fuzzy logic controller to improve its performance for active suspension system.

The remaining part of this paper is organised as follow: Section 2 describes mathematical model of full car model with governing equation. The design of intelligent controller using fuzzy logic carried out in section 3. Section 4 present the result of simulation carried out for different road profile. Conclusion of the work will be presented in section 5 .

\section{Modelling of full car model for active suspension}

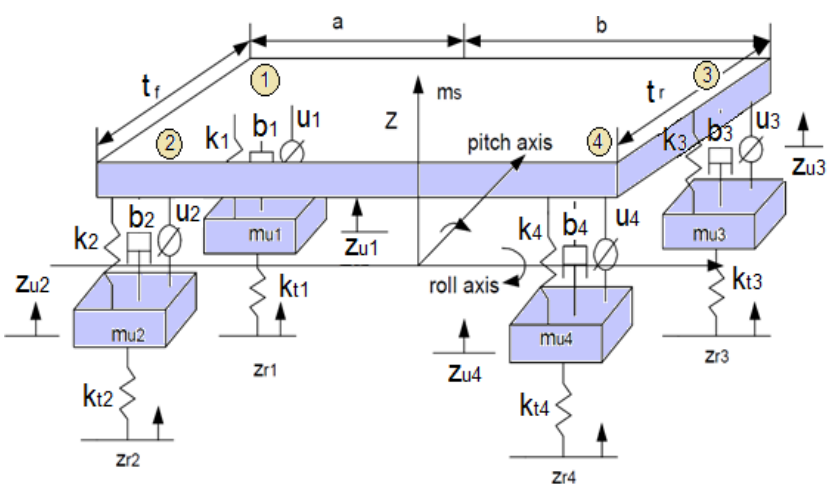

Fig. 1 Schematic representation of 7 DOF full car model

A full car model with 7 degree of freedom (DOF) is shown in Fig. 1. The full car model consists of Vehicle body mass $m_{s}$ and four tires of mass $m_{u 1}, m_{u 2}, m_{u 3}$ and $m_{u 4}$ respectively. The four corners of vehicle body represented by $z_{1}, z_{2}, z_{3}$ and $z_{4}$ respectively in order to measure the vertical displacement of vehicle body at each corner. A spring of stiffness $\mathrm{k}$ and damping coefficient $\mathrm{b}$ along with actuator force $u$ is placed in between vehicle body and tire on each corner. The vertical motion of tire is indicated by $z_{u 1}, \mathrm{z}_{u 2}, z_{u 3}$ and $z_{u 4}$ respectively. The stiffness of tire at each corner is modeled by spring of stiffness kt. The up and down motion of vehicle body along pitch axis is represented by symbol $\theta$. Similarly, $\alpha$ represent rolling motion of vehicle body along roll axis. The displacement of road for each tire on each corner is indicated by road profile $z_{r 1}, z_{r 2}, z_{r 3}$ and $z_{r 4}$. The 7 Degree of freedom of full car model are represented as four vertical tire displacement $\left(z_{u 1}, z_{u 2}, z_{u 3}, z_{u 4}\right)$, heave $\mathrm{z}$, Pitch $\theta$, Roll $\alpha$ of an vehicle body.
The distance of CG from front and rear end of vehicle indicated by symbol $a$ and $b$ respectively. $T_{f}$ and $\mathrm{t}_{\mathrm{r}}$ indicates front and rear treat of vehicle body. The actuator arranged vertically between sprung and unsprung mass has been used to provide actuator force to active suspension system. The full car model has ability to measure the pitch and roll motion of car boy which cannot be possible to measure in quarter car model of vehicle suspension system. A hydraulic actuator is placed on each suspension between sprung and unsprung mass. In this work, the dynamics of actuator is neglected for simulation of full car model. The values of parameter used in full car model listed in Table 1.

Table 1

Values of parameter used in full car model

\begin{tabular}{|c|c|c|}
\hline $\begin{array}{c}\text { Sym- } \\
\text { bol }\end{array}$ & Parameter & Value \\
\hline$m_{s}$ & mass of the car body & $1136 \mathrm{~kg}$ \\
\hline$m_{u 1}$ & mass of the front wheel at corner 1 & $63 \mathrm{~kg}$ \\
\hline$m_{u 2}$ & mass of the front wheel at corner 2 & $63 \mathrm{~kg}$ \\
\hline$m_{u 3}$ & mass of the front wheel at corner 3 & $60 \mathrm{~kg}$ \\
\hline$m_{u 4}$ & mass of the front wheel at corner 4 & $60 \mathrm{~kg}$ \\
\hline$I_{p}$ & Pitch moment of inertia & $2400 \mathrm{kgm}^{2}$ \\
\hline$I_{r}$ & Roll moment of inertia & $400 \mathrm{kgm}^{2}$ \\
\hline$b_{1}$ & $\begin{array}{l}\text { Damping coefficient of front sus- } \\
\text { pension at corner } 1\end{array}$ & $3924 \mathrm{Ns} / \mathrm{m}$ \\
\hline $\mathrm{b}_{2}$ & $\begin{array}{l}\text { Damping coefficient of front sus- } \\
\text { pension at corner } 2\end{array}$ & $3924 \mathrm{Ns} / \mathrm{m}$ \\
\hline$b_{3}$ & $\begin{array}{l}\text { Damping coefficient of rear suspen- } \\
\text { sion at corner } 3\end{array}$ & $2943 \mathrm{Ns} / \mathrm{m}$ \\
\hline$b_{4}$ & $\begin{array}{l}\text { Damping coefficient of rear suspen- } \\
\text { sion at corner } 4\end{array}$ & $2943 \mathrm{Ns} / \mathrm{m}$ \\
\hline$k_{1}$ & $\begin{array}{l}\text { Stiffness of front suspension at cor- } \\
\text { ner } 1\end{array}$ & $36297 \mathrm{~N} / \mathrm{m}$ \\
\hline$k_{2}$ & $\begin{array}{l}\text { Stiffness of front suspension at cor- } \\
\text { ner } 2\end{array}$ & $36297 \mathrm{~N} / \mathrm{m}$ \\
\hline$k_{3}$ & $\begin{array}{l}\text { Stiffness of rear suspension at corner } \\
3\end{array}$ & $19620 \mathrm{~N} / \mathrm{m}$ \\
\hline$k_{4}$ & $\begin{array}{l}\text { Stiffness of rear suspension at corner } \\
4\end{array}$ & $19620 \mathrm{~N} / \mathrm{m}$ \\
\hline$k_{t 1}$ & $\begin{array}{l}\text { Stiffness of front suspension at cor- } \\
\text { ner } 1\end{array}$ & $182470 \mathrm{~N} / \mathrm{m}$ \\
\hline$k_{t 2}$ & $\begin{array}{l}\text { Stiffness of front suspension at cor- } \\
\text { ner } 2\end{array}$ & $182470 \mathrm{~N} / \mathrm{m}$ \\
\hline$k_{t 3}$ & $\begin{array}{l}\text { Stiffness of rear suspension at corner } \\
3\end{array}$ & $182470 \mathrm{~N} / \mathrm{m}$ \\
\hline$k_{t 4}$ & $\begin{array}{l}\text { Stiffness of rear suspension at corner } \\
4\end{array}$ & $182470 \mathrm{~N} / \mathrm{m}$ \\
\hline$a$ & $\begin{array}{l}\text { Distance between front end to CG of } \\
\text { Vehicle body }\end{array}$ & $1.15 \mathrm{~m}$ \\
\hline$b$ & $\begin{array}{l}\text { Distance between rear end to CG of } \\
\text { Vehicle body }\end{array}$ & $1.65 \mathrm{~m}$ \\
\hline$t_{f}$ & Front treat & $0.505 \mathrm{~m}$ \\
\hline$t_{r}$ & Rear treat & $0.557 \mathrm{~m}$ \\
\hline
\end{tabular}


The equation of motion for full car model [23] derived from newton's second law of motion using the schematic diagram of full car model. The equation for heave $\mathrm{z}$, pitch angle, roll angle of vehicle body described in equation (1), (2) and (3):

$$
\begin{aligned}
& I_{r} \ddot{\varphi}=-b_{1} t_{f}\left(\dot{z}_{1}-\dot{z}_{u 1}\right)+b_{2} t_{f}\left(\dot{z}_{2}-\dot{z}_{u 2}\right)-b_{3} t_{r}\left(\dot{z}_{3}-\dot{z}_{u 3}\right)+ \\
& +b_{4} t_{r}\left(\dot{z}_{4}-\dot{z}_{u 4}\right)-k_{1} t_{f}\left(z_{1}-z_{u 1}\right)+k_{2} t_{f}\left(z_{2}-z_{u 2}\right)- \\
& -k_{3} t_{r}\left(z_{3}-z_{u 3}\right)+k_{4} t_{r}\left(z_{4}-z_{u 4}\right)+t_{f} u_{1}-t_{f} u_{2}+t_{r} u_{3}-t_{r} u_{4},
\end{aligned}
$$

$I_{p} \ddot{\theta}=-b_{1} a\left(\dot{z}_{1}-\dot{z}_{u 1}\right)-b_{2} a\left(\dot{z}_{2}-\dot{z}_{u 2}\right)+b_{3} b\left(\dot{z}_{3}-\dot{z}_{u 3}\right)+$

$+b_{4} b\left(\dot{z}_{4}-\dot{z}_{u 4}\right)-k_{1} a\left(z_{1}-z_{u 1}\right)-k_{2} a\left(z_{2}-z_{u 2}\right)+$

$+k_{3} b\left(z_{3}-z_{u 3}\right)+k_{4} b\left(z_{4}-z_{u 4}\right)+a u_{1}+a u_{2}+a u_{3}+a u_{4}$,

$m_{s} \ddot{z}=-b_{1}\left(\dot{z}_{1}-\dot{z}_{u 1}\right)-b_{2}\left(\dot{z}_{2}-\dot{z}_{u 2}\right)-b_{3}\left(\dot{z}_{3}-\dot{z}_{u 3}\right)-$

$-b_{4}\left(\dot{z}_{4}-\dot{z}_{u 4}\right)-k_{1}\left(z_{1}-z_{u 1}\right)-k_{2}\left(z_{2}-z_{u 2}\right)-$

$-k_{3}\left(z_{3}-z_{u 3}\right)-k_{4}\left(z_{4}-z_{u 4}\right)+u_{1}+u_{2}+u_{3}+u_{4}$.

The four vertical motion of tire on each corner for an external disturbance can be described in equations (4-7):

$$
\begin{aligned}
& m_{u 1} \ddot{z}_{u 1}=b_{1}\left(\dot{z}_{1}-\dot{z}_{u 1}\right)+k_{1}\left(\dot{z}_{1}-\dot{z}_{u 1}\right)+k_{t 1}\left(z_{r 1}-z_{u 1}\right)-u_{1}, \\
& m_{u 2} \ddot{z}_{u 2}=b_{2}\left(\dot{z}_{2}-\dot{z}_{u 2}\right)+k_{2}\left(z_{2}-z_{u 2}\right)+k_{t 2}\left(z_{r 2}-z_{u 2}\right)-u_{2}, \\
& m_{u 3} \ddot{z}_{u 3}=b_{3}\left(\dot{z}_{3}-\dot{z}_{u 3}\right)+k_{3}\left(z_{3}-z_{u 3}\right)+k_{t 3}\left(z_{r 3}-z_{u 3}\right)-u_{3}, \\
& m_{u 4} \ddot{z}_{u 4}=b_{4}\left(\dot{z}_{4}-\dot{z}_{u 4}\right)+k_{4}\left(z_{4}-z_{u 4}\right)-k_{t 4}\left(z_{r 4}-z_{u 4}\right)-u_{4} .
\end{aligned}
$$

In the above equation, vertical displacement of car body at corner 1, 2, 3, 4 can be described in equation (8) using heave $z$, pitch angle, roll angle of vehicle body.

Where:

$$
\begin{array}{ll}
z_{1}=z+t_{f} \phi_{s}+a \theta_{s}, & \dot{z}_{1}=\dot{z}+t_{f} \dot{\phi}_{s}+a \dot{\theta}_{s}, \\
z_{2}=z-t_{f} \phi_{s}+a \theta_{s}, & \dot{z}_{2}=\dot{z}-t_{f} \dot{\phi}_{s}+a \dot{\theta}_{s}, \\
z_{3}=z+t_{r} \phi_{s}-b \theta_{s}, & \dot{z}_{3}=\dot{z}+t_{r} \dot{\phi}_{s}-b \dot{\theta}_{s}, \\
z_{4}=z-t_{r} \phi_{s}-b \theta_{s}, & \dot{z}_{4}=\dot{z}-t_{r} \dot{\phi}_{s}-b \dot{\theta}_{s} .
\end{array}
$$

\section{Controller design}

Fuzzy logic controller has ability to handle complexity, nonlinearity and unpredictable behaviour of actuator dynamics in active suspension system. The overall layout of fuzzy controller used in full car modelled active suspension system is shown in Fig. 2. The actual suspension travel of each wheel act as control parameter for fuzzy controller.

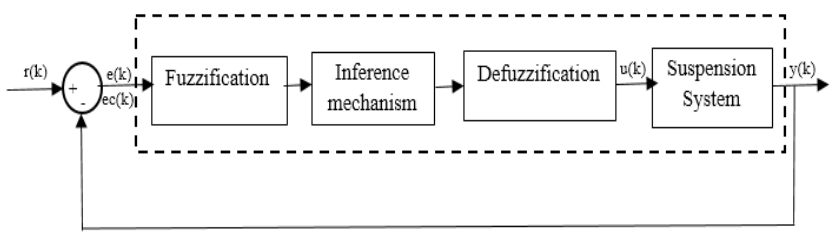

Fig. 2 Overall layout of Fuzzy controller
The fuzzification stage converts the error $e(k)$ and error change $e c(k)$ of suspension deflection into fuzzy values with help of membership function. The fuzzy rules which are designed based on expert knowledge has been applied in inference mechanism.

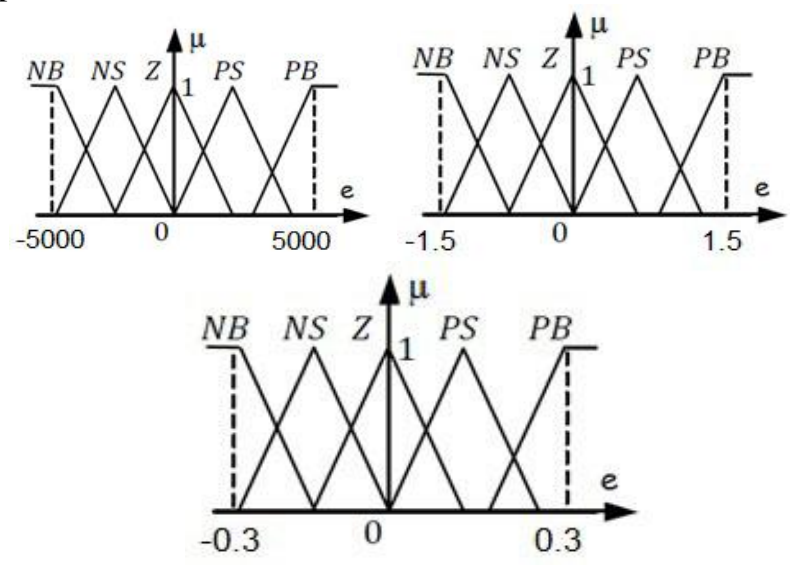

Fig. 3 Membership function for Fuzzy controller

The triangular membership function with five linguistic variable represented in in Fig. 3. These membership function converts the real input data into fuzzy values. A classic interpretation of Mamdani [24] was used as rule basis. The range of input variable and output variable were determined by the simulation results in different conditions. The rules table for fuzzy logic control is shown in Table 2. Minimizing the vertical displacement of the automobile body is the basis of constructing the fuzzy control rules.

Table 2

Fuzzy rules for controller

\begin{tabular}{|c|c|c|c|c|c|}
\hline $\begin{array}{c}e(k) \\
l e c(k)\end{array}$ & NEB & NES & ZER & PES & PEB \\
\hline NEB & NEB & NEB & NES & NES & ZER \\
\hline NES & NEB & NES & NES & ZER & PES \\
\hline ZER & NES & NES & ZER & PES & PES \\
\hline PES & NEM & ZER & PES & PES & PEB \\
\hline PEB & ZER & PES & PES & PEB & PEB \\
\hline
\end{tabular}

The abbreviations used correspond to: NEB: Negative Big; NES: Negative Small; ZER: Zero; PES: Positive Small; PEB: Positive Big; e (k): Error; ec $(\mathrm{k})$ : change in error.

Defuzzification process converts the fuzzy values obtained membership function into real output data as control voltage which drives servo valve. Among the many defuzzification methods, centroid method is simple and easy to use for control application [25]. The centroid defuzzification technique can be expressed as:

$$
Z_{C O G}=\frac{z^{\mu_{A}(Z) Z d z}}{{ }_{Z} \mu_{A}(Z) d z},
$$

where: $Z_{C O G}$ is the crisp output, $\mu_{A}(z)$ is the aggregated membership function and $\mathrm{z}$ is the output variable.

\section{Simulation}

The simulation was carried out for active suspension system using full car model described in section 2 . The 
performance of proposed fuzzy controller measured against passive and Proportional Integral Derivative (PID) control of Active suspension system. The variables namely body displacement, suspension travel, control force, body Acceleration of each wheel measured find the performance of proposed fuzzy controller.

The road input for each wheel of full car model [26-28] indicated in equations (9-11). There will be small change in height of road $Z_{r 1}$ and $Z_{r 2}$ in order to measure the roll angle of full car model.

$$
\begin{aligned}
& Z_{r 1}=\left\{\begin{array}{cc}
0.15(1-\cos (2 \pi t)) & 1 \leq t \leq 2 \\
0 & \text { otherwise }
\end{array} .\right. \\
& Z_{r 2}=\left\{\begin{array}{cc}
0.1(1-\cos (2 \pi t)) & 1 \leq t \leq 2 \\
0 & \text { otherwise }
\end{array} .\right. \\
& Z_{r 3, r 4}=\left\{\begin{array}{cc}
0.1(1-\cos (2 \pi t)) & 6 \leq t \leq 7 \\
0 & \text { otherwise }
\end{array}\right.
\end{aligned}
$$

The response of front wheel at corner 1 for given road profile is represented in Fig. 4 which indicates the response of passive, PID and fuzzy active suspension for various suspension parameter. Table 3 lists the root mean squared values of suspension parameters used for simulation of full car model. The Passive suspension of corner 1 has displacement of $2.94 \mathrm{~cm}$ and long settling time compare to fuzzy controller which has wheel displacement of $2.44 \mathrm{~cm}$ and less settling time. The acceleration of fuzzy controlled suspension is $0.7252 \mathrm{~m} / \mathrm{s}^{2}$ which is far better than $1.01 \mathrm{~m} / \mathrm{s}^{2}$ of passive suspension. Hence a fuzzy controller reduces the body displacement and acceleration of corner 1 better than passive suspension system.

The response of front wheel at corner 2 for given road profile is represented in Fig. 5 which indicates the response of passive, PID and fuzzy active suspension for various suspension parameter. The Passive suspension of corner 2 has displacement of $2.23 \mathrm{~cm}$ and long settling time compare to fuzzy controller which has displacement of 0.79 $\mathrm{cm}$ and less settling time. The acceleration of fuzzy controlled suspension is $0.5063 \mathrm{~m} / \mathrm{s}^{2}$ which is far better than $0.7984 \mathrm{~m} / \mathrm{s}^{2}$ of passive suspension. Hence a fuzzy controller reduces the body displacement and acceleration of corner 2 better than passive suspension system.

The response of front wheel 3 at corner 3 is represented in Fig. 6. The suspension travel of passive suspension of corner 3 is $0.7513 \mathrm{~cm}$ whereas suspension travel of fuzzy controller is $0.2407 \mathrm{~cm}$. The acceleration of fuzzy controlled suspension is $0.4786 \mathrm{~m} / \mathrm{s}^{2}$ which is better than $0.6226 \mathrm{~m} / \mathrm{s}^{2}$ of passive suspension. So, fuzzy controller reduces suspension travel and acceleration better than passive suspension system.

The response of front wheel 4 at corner 4 for given road profile is represented in Fig. 7 which indicates the response of passive, PID and fuzzy active suspension for various suspension parameter. The Passive suspension of corner 4 has displacement of $2.04 \mathrm{~cm}$ and long settling time compare to fuzzy controller which has displacement of $1.674 \mathrm{~cm}$ and less settling time. The acceleration of fuzzy controlled suspension is $0.4865 \mathrm{~m} / \mathrm{s}^{2}$ which is far better than
$0.6406 \mathrm{~m} / \mathrm{s}^{2}$ passive suspension. Hence a fuzzy controller reduces the body displacement and acceleration better than passive suspension system.

Table 3 lists root mean squared values of displacement, suspension travel and acceleration of corner at 1,2,3, 4 respectively. It also indicates displacement, pitch angle, roll angle of whole body for passive, PID and fuzzy controlled suspension system. This result indicates that fuzzy controller reduces suspension travel and vertical acceleration amplitude of suspension significantly compare to passive and PID suspension. It indicates that the ride comfort of the passengers is improved greatly by using the proposed Fuzzy logic controller.

\begin{tabular}{|c|c|c|c|c|}
\hline \multirow{2}{*}{ Position } & \multirow{2}{*}{ Parameter } & \multicolumn{3}{|c|}{ Root Mean Squared Value } \\
\hline & & Passive & PID & Fuzzy \\
\hline \multirow{3}{*}{ Corner 1} & $\begin{array}{l}\text { Displacement } \\
(\mathrm{cm})\end{array}$ & 2.9462 & 2.4974 & 2.4452 \\
\hline & $\begin{array}{l}\text { Suspension } \\
\text { Travel }(\mathrm{cm})\end{array}$ & 0.8764 & 0.2626 & 0.1745 \\
\hline & $\begin{array}{l}\text { Acceleration } \\
\left(\mathrm{m} / \mathrm{s}^{2}\right)\end{array}$ & 1.0106 & 0.6583 & 0.7252 \\
\hline \multirow[t]{3}{*}{ Corner 2} & $\begin{array}{l}\text { Displacement } \\
(\mathrm{cm})\end{array}$ & 2.2378 & 1.9673 & 1.9349 \\
\hline & $\begin{array}{l}\text { Suspension } \\
\text { Travel (cm) }\end{array}$ & 0.7633 & 0.3512 & 0.2478 \\
\hline & $\begin{array}{l}\text { Acceleration } \\
\left(\mathrm{m} / \mathrm{s}^{2}\right)\end{array}$ & 0.7984 & 0.5336 & 0.5063 \\
\hline \multirow{3}{*}{ Corner 3} & $\begin{array}{l}\text { Displacement } \\
(\mathrm{cm})\end{array}$ & 2.0168 & 1.6943 & 1.666 \\
\hline & $\begin{array}{l}\text { Suspension } \\
\text { Travel (cm) }\end{array}$ & 0.7513 & 0.2965 & 0.2407 \\
\hline & $\begin{array}{l}\text { Acceleration } \\
\left(\mathrm{m} / \mathrm{s}^{2}\right)\end{array}$ & 0.6226 & 0.4349 & 0.4786 \\
\hline \multirow[t]{3}{*}{ Corner 4} & $\begin{array}{l}\text { Displacement } \\
(\mathrm{cm})\end{array}$ & 2.0416 & 1.6971 & 1.674 \\
\hline & $\begin{array}{l}\text { Suspension } \\
\text { Travel }(\mathrm{cm}) \\
\end{array}$ & .8040 & 0.3080 & 0.2874 \\
\hline & $\begin{array}{l}\text { Acceleration } \\
\left(\mathrm{m} / \mathrm{s}^{2}\right)\end{array}$ & 0.6406 & 0.4363 & .48654 \\
\hline \multirow[t]{4}{*}{ Body } & $\begin{array}{l}\text { Displacement } \\
(\mathrm{m})\end{array}$ & 1.710 & 1.4792 & 1.442 \\
\hline & $\begin{array}{l}\text { Acceleration } \\
\left(\mathrm{m} / \mathrm{s}^{2}\right)\end{array}$ & 0.5832 & 0.3917 & 0.4288 \\
\hline & $\begin{array}{l}\text { Pitch angle } \\
\text { (Deg) }\end{array}$ & 0.6774 & 0.5722 & 0.5667 \\
\hline & $\begin{array}{l}\text { Roll Angle } \\
\text { (Deg) }\end{array}$ & 0.4141 & 0.3037 & 0.2927 \\
\hline
\end{tabular}

Table 3

Root mean squared value of suspension parameter

The whole body vertical motion about CG indicated by body displacement. The vehicle body motion for given road profile is represented in Fig. 8. The body displacement of fuzzy controlled suspension is $1.442 \mathrm{~cm}$ which is less than $1.710 \mathrm{~cm}$ of passive suspension. The acceleration of vehicle body in Fig. 9 indicates that fuzzy controlled suspension has acceleration of $0.4288 \mathrm{~m} / \mathrm{s}^{2}$ which is less than passive suspension system. This simulation results shows that fuzzy controlled suspension for full car model provide better ride comfort and stability than passive suspension system. The performance of proposed controller mainly depends on body displacement, acceleration, roll and pitch angle of full car model. But the roll and pitch angle cannot be measured in quarter car model of active suspension system. 


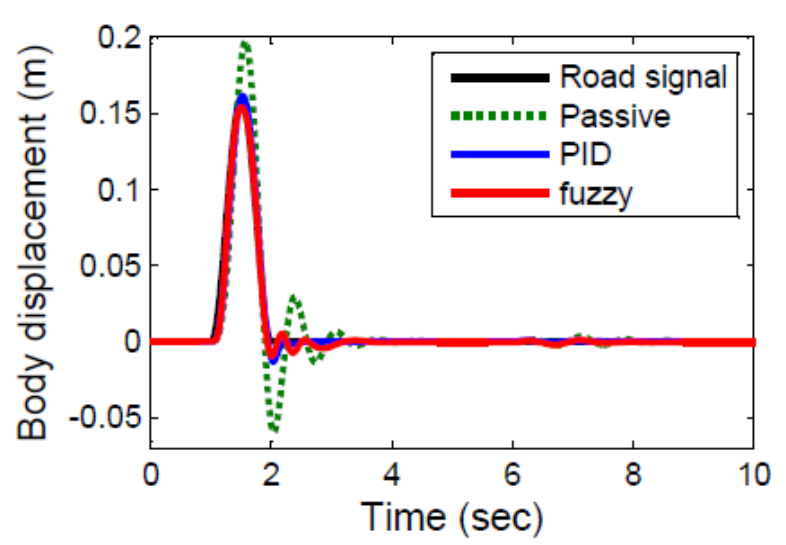

(a) Body displacement

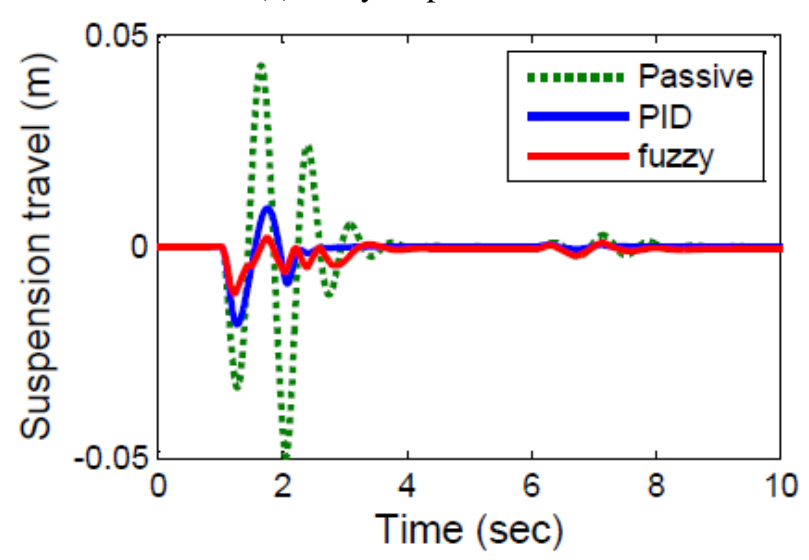

(b) Suspension travel

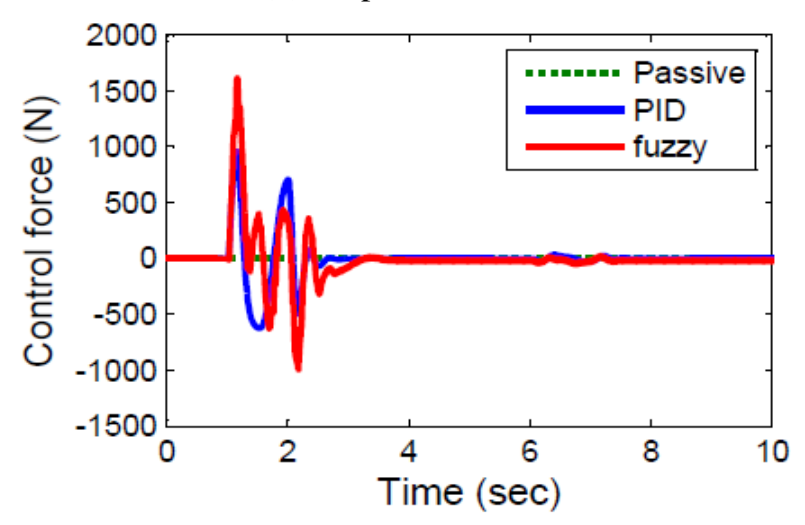

(c) Control force

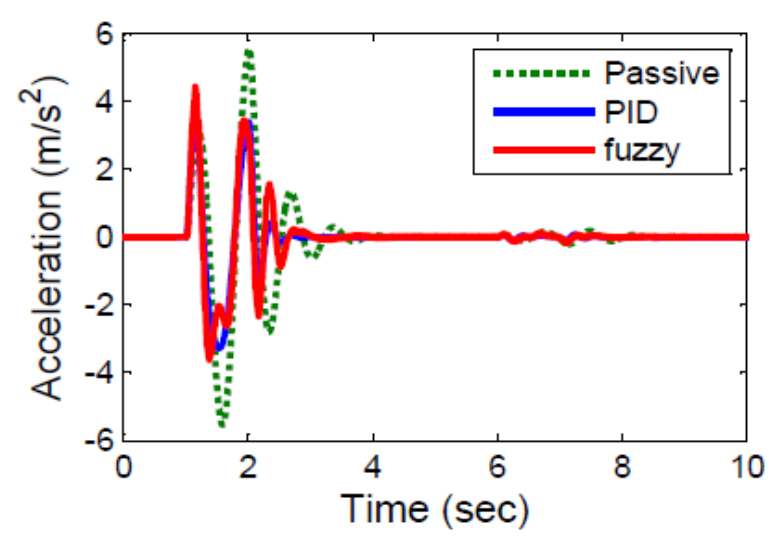

(d) Acceleration

Fig. 4 Response of wheel 1 for road profile

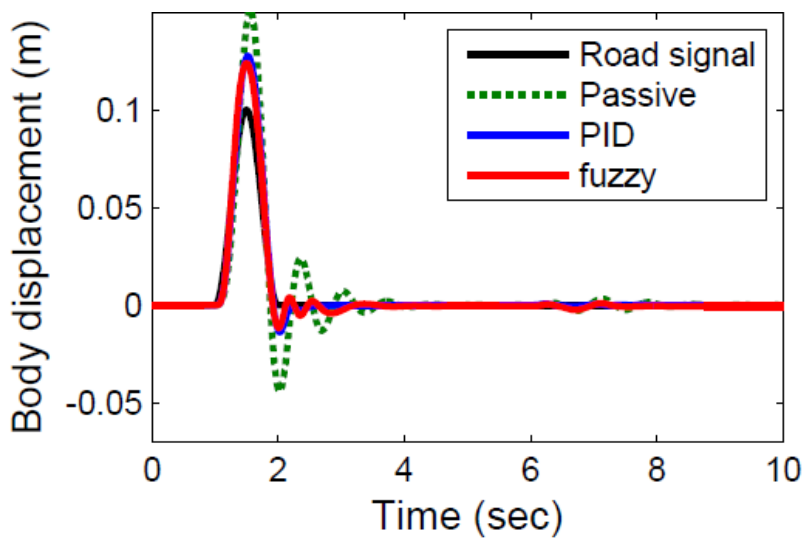

(a) Body displacement

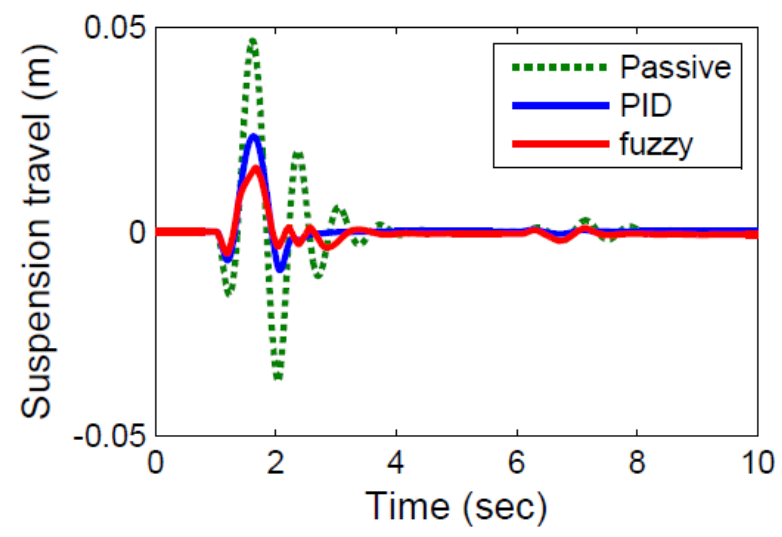

(b) Suspension travel

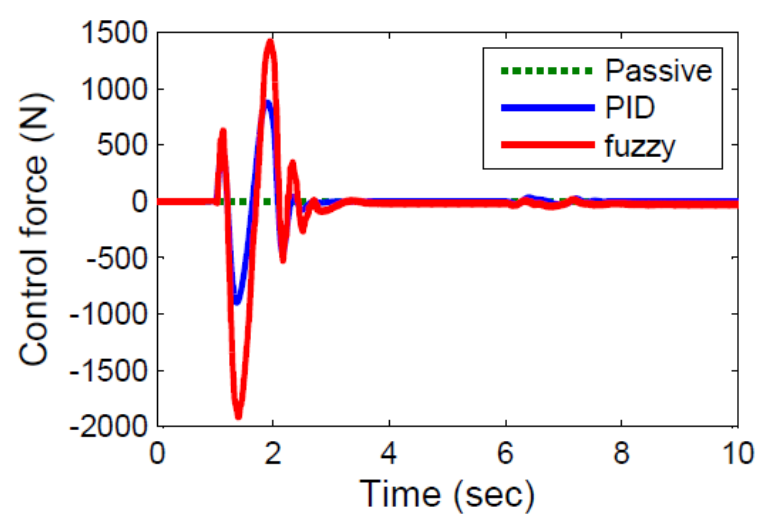

(c) Control force

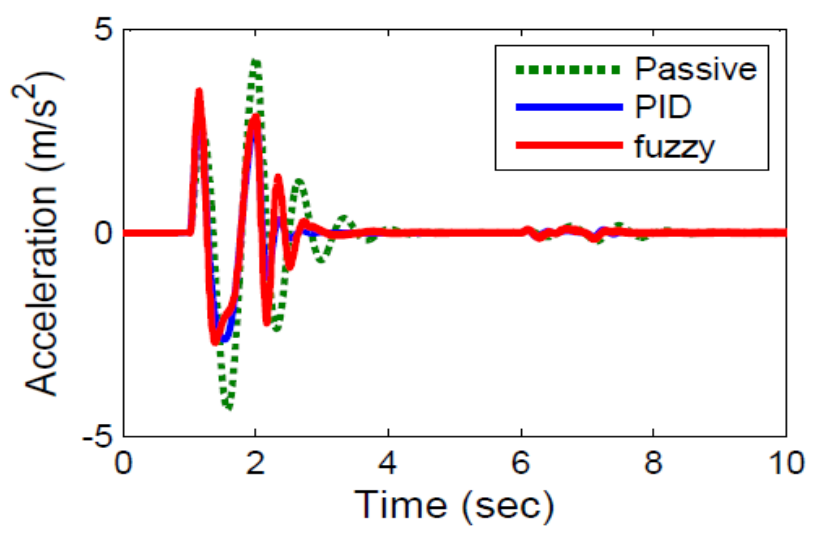

(d) Acceleration

Fig. 5 Response of wheel 2 for road profile 


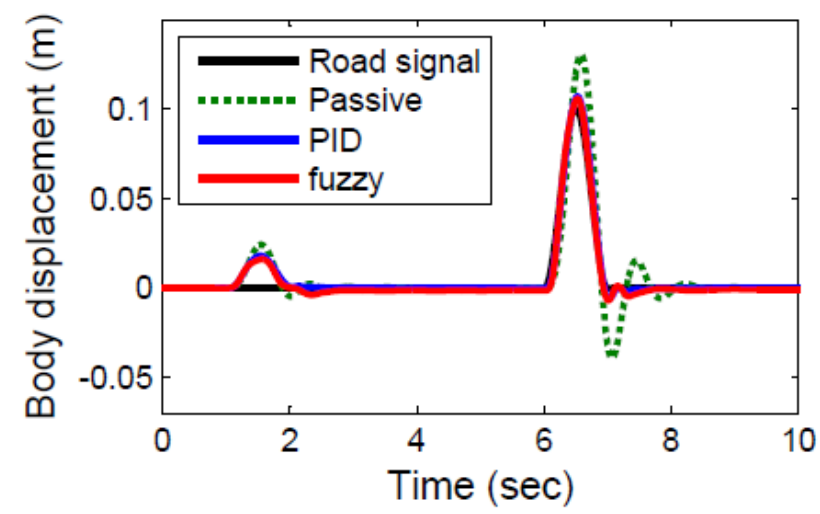

(a) Body displacement

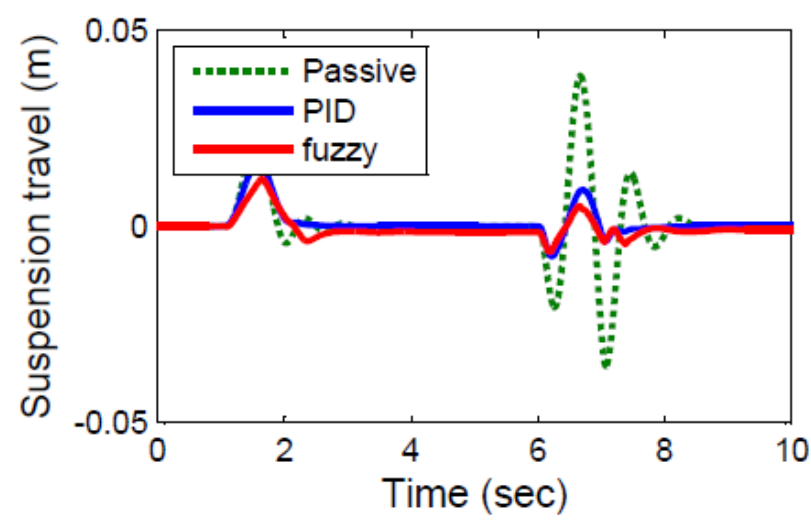

(b) Suspension travel

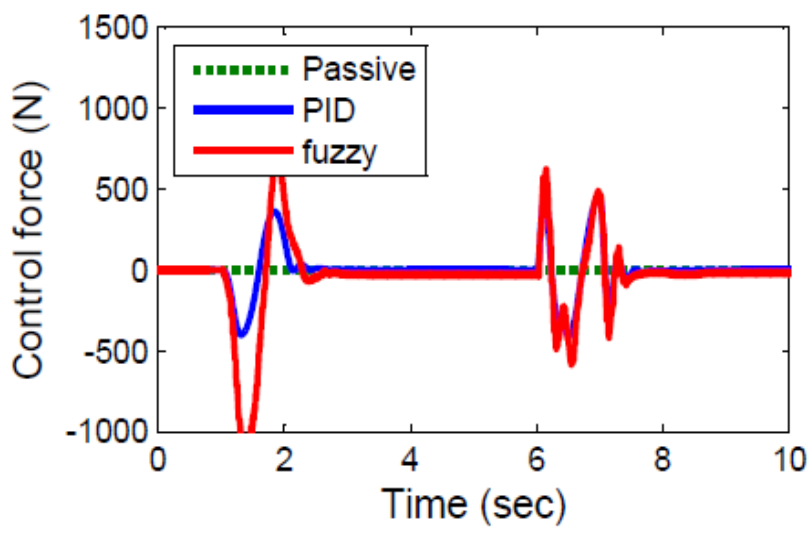

(c) Control Force

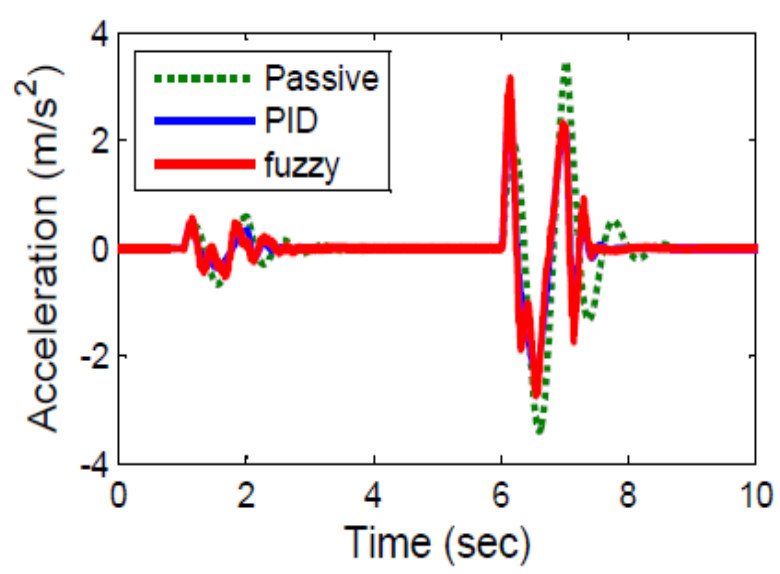

(d) Acceleration

Fig. 6 Response of wheel 3 for road profile

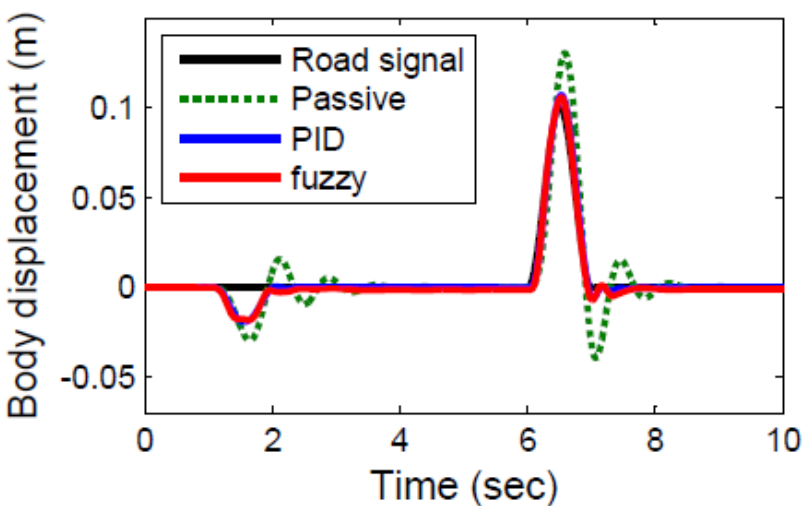

(a) Body displacement

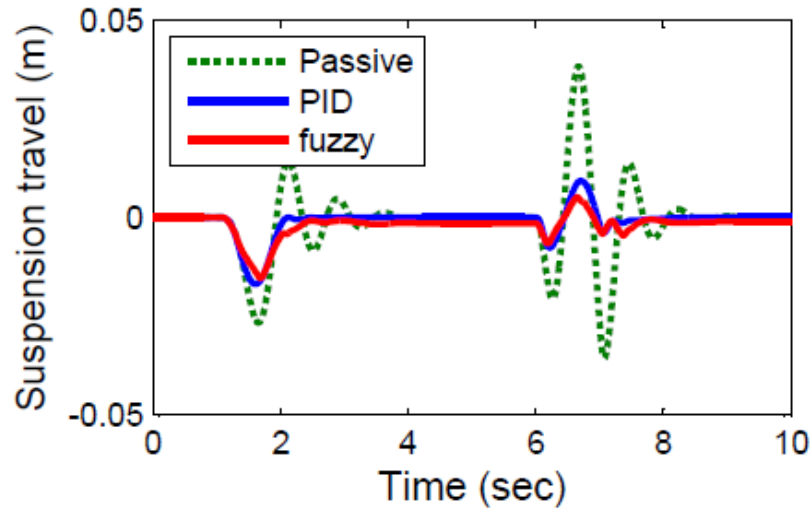

(b)Suspension travel

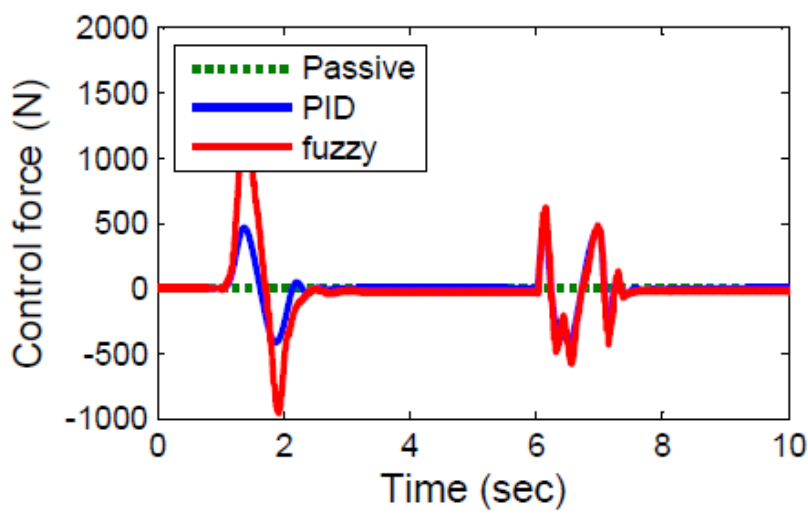

(c) Control Force

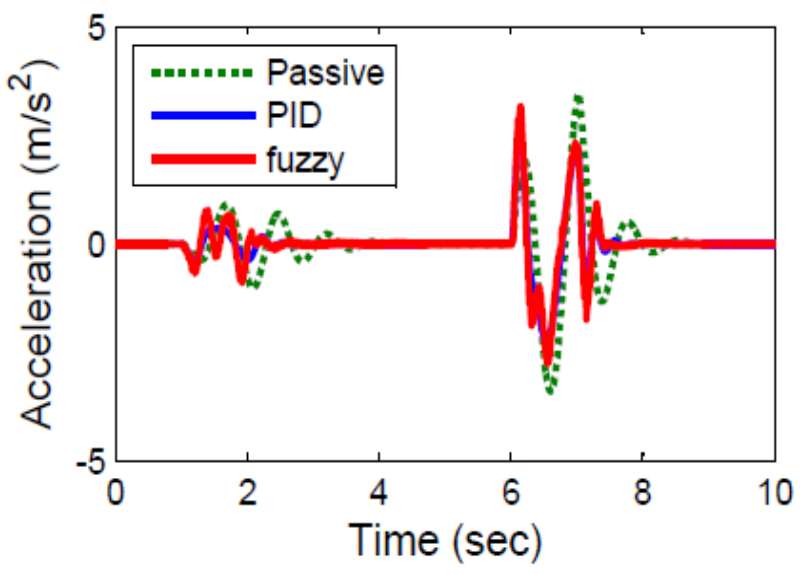

(d) Acceleration

Fig. 7 Response of wheel 4 for road profile 


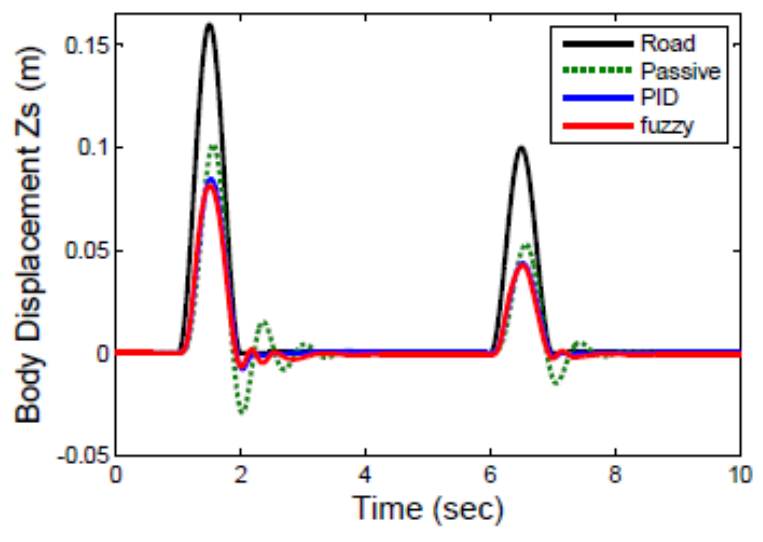

Fig. 8 Response of body displacement

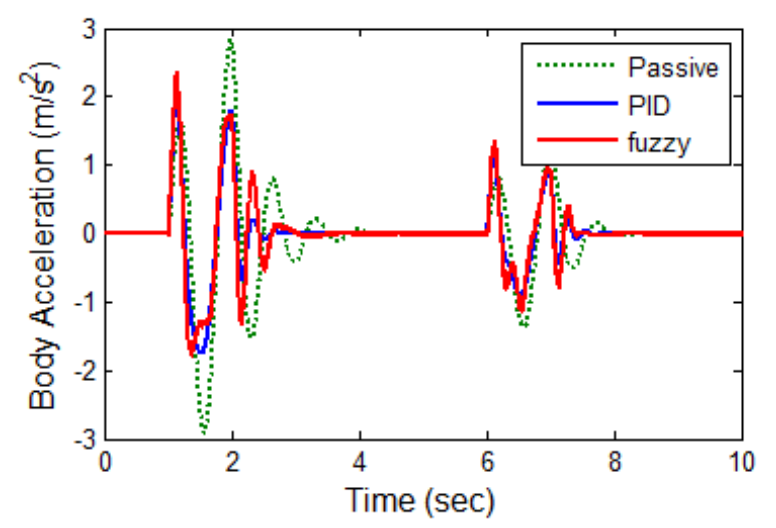

Fig. 9 Response body acceleration

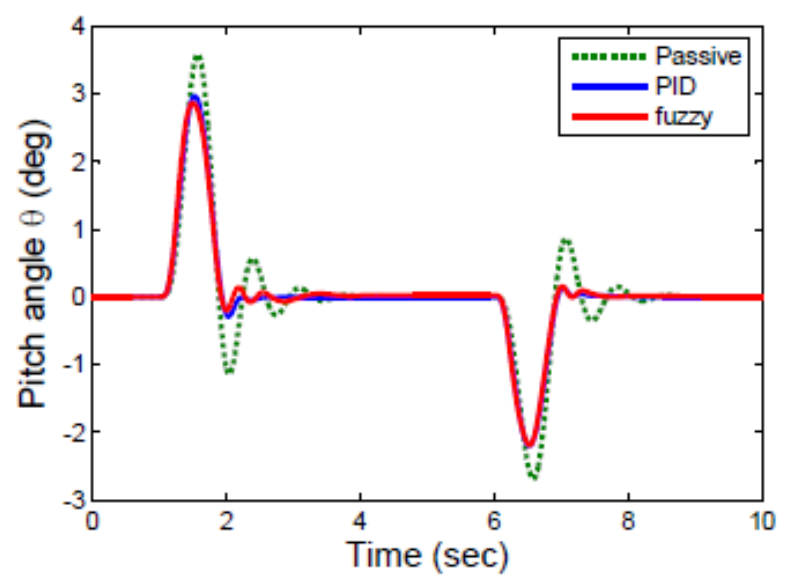

Fig. 10 Response of pitch angle

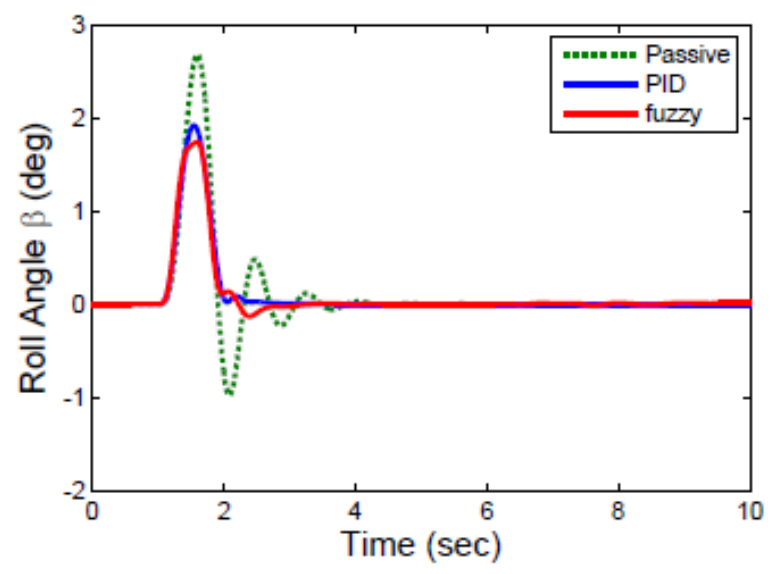

Fig. 11 Response of roll angle

The up and down motion of vehicle body about pitch axis is represented by pitch angle. The pitch angle of passive, PID and fuzzy controlled suspension represented in Fig. 10. The fuzzy controlled suspension has less deviation of pitch angle compare to deviation of passive suspension system. The oscillating motion of whole body about roll axis indicated by roll angle. The rolling angle of passive, PID and fuzzy controlled suspension represented in Fig. 11. The fuzzy controller based active suspension has less deviation compare to passive suspension system.

\section{Conclusions}

The seven-degree-of-freedom full car model based suspension has nonlinear characteristics as a result of its hydraulic components has increased the difficulty of creating mathematical model for active suspension system. In real time, the model based controller do not give better result due to its nonlinear behaviour of actuators used in active suspension system. The proposed fuzzy controller results have demonstrated that the magnitudes of the body displacement and acceleration are decreased as well as the resonance peak due to vehicle body is eliminated significantly compare to model based controller. The simulation of proposed fuzzy controller for active suspension system has confirmed improvement of the ride comfort in vehicles.

\section{References}

1. Cao, J.; Liu, H.; Li, P.; Brown, D. J. 2008. State of the art in vehicle active suspension adaptive control systems based on intelligent methodologies, IEEE transactions on intelligent transportation systems, 9(3): 392-405. http://dx.doi.org/ 10.1109/TITS.2008.928244.

2. Hrovat. D. 1990. Optimal active suspension structures for quarter-car vehicle models, Automatica 25(5): 845860 .

https://doi.org/10.1016/0005-1098(90)90002-Y.

3. Thompson, A; Davis, B. 1988. Optimal linear active suspensions with derivative constraints and output feedback control, Vehicle System Dynamics, 17(4):179-192. http://dx.doi.org/10.1080/00423118808968901.

4. Alleyne, A. G.; Liu, R. 2000. Systematic control of a class of nonlinear systems with application to electrohydraulic cylinder pressure control, IEEE transactions on control systems technology, 8(4): 623-634. http://dx.doi.org/ 10.1109/87.852908.

5. Yagiz, N.; Hacioglu, Y.; Taskin, Y. 2008. Fuzzy sliding-mode control of active suspensions. IEEE Transactions on industrial electronics, 55(11): 3883-3890. http://dx.doi.org/ 10.1109/TIE.2008.924912.

6. Sun, W.; Gao, H.; Yao, B. 2013. Adaptive robust vibration control of full-car active suspensions with electrohydraulic actuators, IEEE Transactions on Control Systems Technology, 21(6): 2417-2422. http://dx.doi.org/10.1109/TCST.2012.2237174.

7. Gohrle, C.; Schindler, A.; Wagner, A.; Sawodny, O. 2014. Design and vehicle implementation of preview active suspension controllers, IEEE Transactions on Control Systems Technology, 22(3): 1135-1142. http://dx.doi.org/10.1109/TCST.2013.2272342.

8. Zadeh, L.A. 1965. Fuzzy sets, Information and control, 8(3): 338-353. https://doi.org/10.2307/2272014.

9. Procyk, T. J.; Mamdani, E. H. 1979. A linguistic selforganizing process controller, Automatica, 15(1): 15-30. 
https://doi.org/10.1016/0005-1098(79)90084-0.

10. Takagi, T.; Sugeno, M. 1985. Fuzzy identification of systems and its applications to modeling and control. IEEE transactions on systems, man, and cybernetics, (1): $116-132$ http://dx.doi.org/10.1109/TSMC.1985.6313399.

11. Rao, M. V. C.; Prahlad, V. 1997. A tunable fuzzy logic controller for vehicle-active suspension systems, Fuzzy sets and systems, 85(1): 11-21. https://doi.org/10.1016/0165-0114(95)00369-X.

12. D'Amato, F. J.; Viassolo, D. E. 2000. Fuzzy control for active suspensions, Mechatronics, 10(8): 897-920. https://doi.org/10.21595/jve.2016.16699.

13. Huang, S. J.; Chao, H. C. 2000. Fuzzy logic controller for a vehicle active suspension system, Proceedings of the Institution of Mechanical Engineers, Part D: Journal of Automobile Engineering, 214(1): 1-12. https://doi.org/10.1243/0954407001527178.

14. Rajagopal, K.; Ponnusamy, L. 2014. Biogeographybased optimization of PID tuning parameters for the vibration control of active suspension system, Journal of Control Engineering and Applied Informatics, 16(1): 3139.

15. Lin, J., Lian, R. J.; Huang, C. N.; Sie, W. T. 2009. Enhanced fuzzy sliding mode controller for active suspension systems, Mechatronics, 19(7): 1178-1190. https://doi.org/10.1016/j.mechatronics.2009.03.009.

16. Cao, J.; Li, P.; Liu, H. 2010. An interval fuzzy controller for vehicle active suspension systems, IEEE Transactions on Intelligent Transportation Systems, 11(4): 885-895.

http://dx.doi.org/10.1109/TITS.2010.2053358.

17. Chen, P. C.; Huang, A. C. 2006. Adaptive sliding control of active suspension systems with uncertain hydraulic actuator dynamics, Vehicle System Dynamics, 44(5): 357-368. http://dx.doi.org/10.1080/00423110600621664.

18. Eski, I.; Yildirim, S. 2009. Vibration control of vehicle active suspension system using a new robust neural network control system, Simulation Modelling Practice and Theory, 17(5): 778-793. https://doi.org/10.1016/j.simpat.2009.01.004.

19. Alleyne A.; Hedrick, J. K. 1995. Nonlinear adaptive control of active suspensions, IEEE transactions on control systems technology, 3(1): 94-10.1 http://dx.doi.org/ 10.1109/87.370714.

20. Park, S. and Rahmdel, S., 2013. A new fuzzy sliding mode controller with auto-adjustable saturation boundary layers implemented on vehicle suspension, International Journal of Engineering-Transactions C: Aspects, 26(12): 1401.

https://doi.org/10.5829/idosi.ije.2013.26.12c.01.

21. Huang, S. J.; Lin, W. C. 2003. Adaptive fuzzy controller with sliding surface for vehicle suspension control. IEEE transactions on fuzzy systems, 11(4): 550-559. http://dx.doi.org/10.1109/TFUZZ.2003.814845.

22. Li, H..; Yu, J.; Hilton, C. and Liu, H. 2013. Adaptive sliding-mode control for nonlinear active suspension vehicle systems using T-S fuzzy approach, IEEE Transactions on Industrial Electronics, 60(8): 3328-3338. http://dx.doi.org/10.1109/TIE.2012.2202354.

23. Darus, R.; Sam, Y.M. 2009. Modeling and control active suspension system for a full car model, IEEE Conference in Signal Processing \& Its Applications, 13-18.
http://dx.doi.org/10.1109/CSPA.2009.5069178.

24. Cherry, A. S.; Jones, R. P. 1995. Fuzzy logic control of an automotive suspension system, IEE ProceedingsControl Theory and Applications, 142(2): 149-160. http://dx.doi.org/10.1049/ip-cta:19951736.

25. Naaz, S.; Alam, A.; Biswas, R. 2011. Effect of different defuzzification methods in a fuzzy based load balancing application, International Journal of Computer Science Issues, 8(5).

26. Nawa, N. E.; Furuhashi, T.; Hashiyama, T.; Uchikawa, Y. 1999. A study on the discovery of relevant fuzzy rules using pseudobacterial genetic algorithm, IEEE Transactions on Industrial Electronics, 46(6): 1080-1089. http://dx.doi.org/10.1109/41.807990.

27. Taghirad, H. D.; Esmailzadeh, E. 1998. Automobile passenger comfort assured through LQG/LQR active suspension, Journal of vibration and control, 4(5): 603618. https://doi.org/10.1177/107754639800400504.

28. Yu, M., Chol, S. B.; Dong, X. and Liao, C. 2008. Fuzzy neural network control for vehicle stability utilizing magneto rheological suspension system, Journal of Intelligent Material Systems and Structures, 20(4): 457466. https://doi.org/10.1177/1045389X08091972.

\author{
P. Senthilkumar, K. Sivakumar, R. Kanagarajan, \\ S. Kuberan
}

\section{FUZZY CONTROL OF ACTIVE SUSPENSION SYSTEM USING FULL CAR MODEL}

S u m m a r y

Fuzzy logic technique has been proposed to control full car model based active suspension system. The full car model has been used to simulate the mathematical model of active suspension system. The performance of proposed controller mainly depends on body displacement, acceleration, roll and pitch angle of full car model. But the roll and pitch angle cannot be measured in quarter car model of active suspension system. The dynamic nature of suspension system and complex nonlinear characteristics of actuating system has increased the difficulty of creating mathematical model for active suspension system. In real time, the controller designed based on analytical method will not give better result due to its complex mathematical model. The fuzzy logic technique has able to give better performance for active suspension system irrespective of the complex nature of mathematical model of suspension system. This paper describes mathematical model of suspension system with fuzzy controller in order to obtain vehicle response for range of road input. The result of simulation will confirm the performance of fuzzy logic controller for active suspension system.

Keywords: Fuzzy logic, Full car model, Active suspension. PID control.

Received January 23, 2017 Accepted April 18, 2018 